\title{
Speckle Tracking Echocardiography for the Assessment of the Athlete's Heart: Is It Ready for Daily Practice?
}

Lynsey Forsythe, PhD

Keith George, PhD

David Oxborough, PhD*

\author{
Address \\ * Research Institute for Sport and Exercise Sciences, Liverpool John Moores \\ University, Tom Reilly Building, Liverpool, L3 3AF, UK \\ Email: d.l.oxborough@ljmu.ac.uk
}

Published online: 27 August 2018

(C) The Author(s) 2018

This article is part of the Topical Collection on Sports Imaging

Keywords Echocardiography $\cdot$ Strain $\cdot$ Athletes heart · Cardiac screening

\section{Abstract}

Purpose of review To describe the use of speckle tracking echocardiography (STE) in the biventricular assessment of athletes' heart (AH). Can STE aid differential diagnosis during pre-participation cardiac screening (PCS) of athletes?

Recent findings Data from recent patient, population and athlete studies suggest potential discriminatory value of STE, alongside standard echocardiographic measurements, in the early detection of clinically relevant systolic dysfunction. STE can also contribute to subsequent prognosis and risk stratification.

Summary Despite some heterogeneity in STE data in athletes, left ventricular global longitudinal strain (GLS) and right ventricular longitudinal strain (RV $\varepsilon$ ) indices can add to differential diagnostic protocols in PCS. STE should be used in addition to standard echocardiographic tools and be conducted by an experienced operator with significant knowledge of the $\mathrm{AH}$. Other indices, including left ventricular circumferential strain and twist, may provide insight, but further research in clinical and athletic populations is warranted. This review also raises the potential role for STE measures performed during exercise as well as in serial follow-up as a method to improve diagnostic yield. 


\section{Introduction}

Echocardiography has advanced our knowledge and understanding of the structural and functional adaptation that occurs in the athletes' heart (AH) in response to chronic training [1-4]. Whilst many different factors can influence cardiac adaptation in the athlete including sex, age, ethnicity, body size, genetics, training volume, type of sport and competitive level [5], common phenotypic descriptions of the $\mathrm{AH}$ have been reported in the literature. Normal physiological remodelling of the left ventricle (LV) can include cavity dilatation, increased wall thickness, normal or slightly reduced systolic function [6] and normal or enhanced diastolic function $[1,3,7]$. Physiological adaptation in the right ventricle (RV) can be characterised by cavity dilatation with normal wall thickness and normal systolic and diastolic function $[8,9]$.

Cardiac chamber enlargement and impaired functional parameters can be also associated with pathological disease, more specifically, cardiomyopathy including hypertrophic cardiomyopathy (HCM), dilated cardiomyopathy (DCM) and arrhythmogenic right ventricular cardiomyopathy (ARVC) [10]. This creates a diagnostic dilemma or 'grey zone' between normal physiological adaptation and potential pathological disease [10]. Although sudden cardiac death (SCD) in athletes is rare (approximately 1 in 50,000) [11], athletes are at greater risk if they have an undetected, underlying condition. In view of this, there is now a growing awareness for the need for pre-participation cardiac screening (PCS) for sports participation to identify those at risk of SCD and it is mandated by many national and international sports federations [12]. Echocardiography is an integral part of PCS, and recent advances in technology such as speckle tracking echocardiography (STE) provide additional global and regional functional assessment of chamber mechanics [13]. This review focusses on the use of strain $(\varepsilon)$ imaging by STE in the assessment of the AH and assesses the potential of the technique to aid differential diagnosis during PCS.

\section{Speckle tracking echocardiography—the rationale}

Currently, the most commonly used $\varepsilon$ imaging modality for assessment of cardiac mechanics is STE. This technique allows for estimation of myocardial $\varepsilon$ to identify local shortening, thickening and lengthening of the myocardium and provides quantitative measurements of $\mathrm{LV}$ regional and global function [14]. $\varepsilon$ describes the myocardial deformation or fractional change in length of a myocardial segment and is expressed as a percentage of its length at end diastole [13]. It can be measured in the longitudinal, circumferential and radial planes of LV motion as well as in the assessment of LV rotation and twist [13].

$\mathrm{RV}$ function assessment by conventional 2D echocardiography is challenging due to the complex RV geometry and the heavily trabeculated inner wall contour [15]. Due to the dominance of longitudinal and oblique myocardial fibres in the RV free wall [15], STE can aid functional assessment by the measurement of RV longitudinal $\varepsilon(\mathrm{RV} \varepsilon)$ [16]. Peak RV $\varepsilon$ is expressed as a mean of the basal, mid and apical segmental $\varepsilon$ with normal RV $\varepsilon$ parameters showing a base to apex gradient with highest values observed at the apex [17].

Standard echocardiographic global functional assessment of the LV is limited by the perception that normal LV ejection fraction (LVEF) equals normal systolic function and that abnormal LVEF equals abnormal function. This may not always be the case and is highlighted by recent studies of pathological hypertension in patients diagnosed with heart failure with normal ejection fraction (HFNEF). HFNEF patients have by definition normal LVEF were systolic function and contractility have been assumed to be normal [18] but there is a paradox of reduced longitudinal, circumferential and radial $\varepsilon$ with normal 
absolute radial thickening and therefore LVEF. Normal LVEF can be explained by the increased diastolic wall thickness $[19,20]$. The terms LVEF and LV function are not synonymous and in the context of increased wall thickness, normal absolute radial thickening results in normal $\mathrm{EF}$ with the illusion of normal pump function [20]. Longitudinal function appears to precede radial dysfunction in many pathological models [21] which has contributed to the adoption of $\varepsilon$ imaging in the early detection of sub-clinical LV dysfunction as well as being a prognostic indicator $[22,23,24]$. With altered $\varepsilon$ indices being reported in cardiomyopathy patients [14], the use of STE in cardiac disease highlights the possibility of STE improving the diagnostic capability of echocardiography in the $\mathrm{AH}$. When we consider that many athletes have marked structural remodelling and given that functional abnormalities are likely to be subtle at an early stage, this review raises the question as to whether the addition of STE improves the sensitivity and specificity of echocardiography in PCS?

\section{Speckle tracking echocardiography and the $\mathrm{AH}$}

\section{LV global longitudinal strain}

LV global longitudinal strain (GLS) is the most frequently reported deformation parameter in clinical and AH studies [25••] and it is now considered a more sensitive measure of systolic function than LVEF in the identification of subclinical LV dysfunction [14]. Recent meta-analyses and systematic reviews have highlighted a number of STE studies in athletes in comparison to controls,

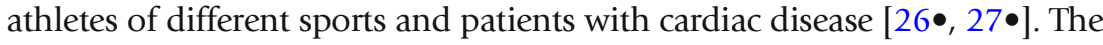
findings are heterogeneous with some studies demonstrating higher GLS in athletes compared to controls $[28,29]$ others showing no differences [30, 31, $32]$ and others showing lower values in the athlete $[33,34]$. This disparity is likely a consequence of a variation in LV structure secondary to the training type and volume. Variable $\varepsilon$ parameters were found when assessing different sporting disciplines which were subsequently normalised following indexing for $\mathrm{LV}$ end diastolic volume [35]. In addition, a recent publication demonstrates a clear relationship between LV morphology, strain and ejection fraction [36]. Female athletes have also been found to have higher GLS than male athletes [37] suggesting that further research is needed in STE and gender differences. In a longitudinal training study of athletes (soccer, basketball and volleyball) involved in an 18-week training study, only a mild increase in GLS, associated with heart rate (HR) and LV size, was observed despite significant increases in LV mass, LV internal dimension in diastole (LVIDd) and systolic volume [38]. Recent European guidelines [25••] demonstrate that GLS in the general population can be variable, as in athletes, and the current normal GLS range has been reported as -16 to $-22 \%$ with a mean of $-20 \%$.

When considering the differentiation from pathology, a study of athletes, controls and hypertensive patients [39] demonstrated significantly lower GLS in hypertensive patients with another study demonstrating similar findings [40]. These studies highlight the potential of STE and a reduction in GLS as an early sign of LV dysfunction. Patients with HCM have been found to have lower GLS compared to controls [41] with Kansal et al. [33] and Butz et al. [42] demonstrating lower GLS in HCM patients compared to athletes. An exemplar representation of LV GLS in an athlete and an HCM patient is presented in Fig. 1a, b. In a study of DCM patients, decreased GLS was observed even in the setting of 

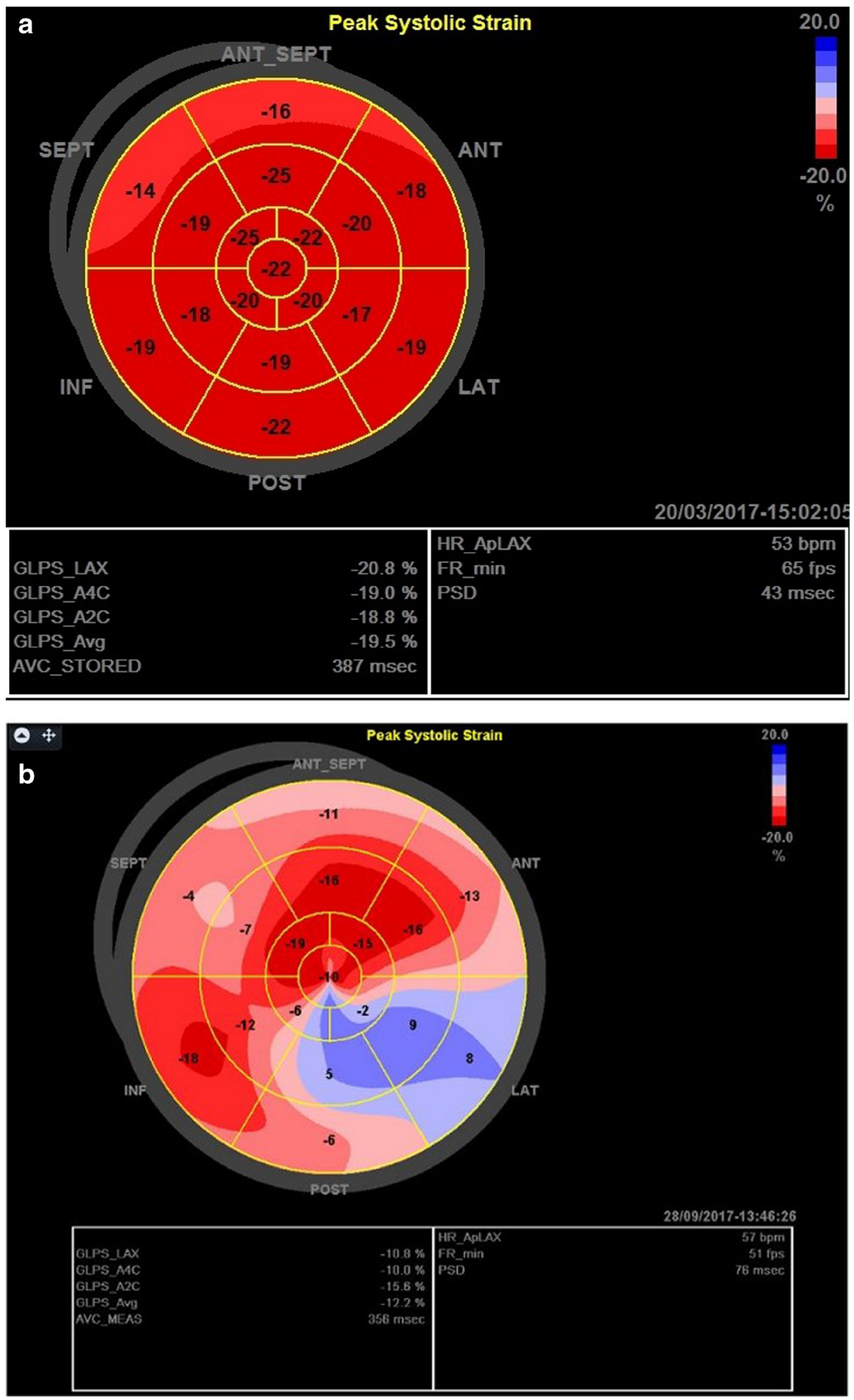

Fig. 1. Bullseye representation of GLS. a Normal elite athlete. $\mathbf{b}$ HCM patient. 
normal EF highlighting the potential of GLS as an early marker of DCM and in serial assessment of systolic function [43]. The reduction in GLS in hypertensive, DCM and HCM patients has prognostic significance suggesting a maladaptive association with cardiovascular pathology and therefore offers potential in the differentiation of these conditions from AH. STE may therefore improve the sensitivity and specificity for the differentiation of cardiomyopathy identifying subtle structural-functional alterations. Based on this, the European guidelines suggest that GLS of less than $-15 \%$ may be indicative of myocardial

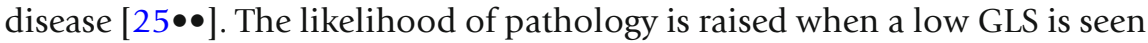
alongside increases in relative wall thickness and/or significant LV dilatation $[27 \bullet, 33]$.

\section{LV circumferential and radial strain}

Fewer studies report global circumferential strain (GCS) and global radial strain (GRS) in the AH. Nottin et al. [44] reported little or no differences in circumferential $\varepsilon$ but observed lower peak apical radial $\varepsilon$ during systole in cyclists compared to controls. No differences in GCS or GRS were reported in a study of sedentary and trained subjects [45], and likewise, no differences in GCS and GRS were reported in athletes from different sporting categories (endurance, strength, mixed) compared to controls [28]. Szauder et al. [46] reported that bodybuilders have lower GCS than marathon runners which is also supported by data from Utomi et al. [30]. The recent meta-analysis [26•] concluded that there are no differences in GCS between athletes and controls, but when categorised for sporting type, resistance athletes may have lower values creating a diagnostic quandary in those athletes.

GCS and GRS were similar between controls, rowers and early hypertensive patients [40]. Patients with HCM have been found to have lower values of LV radial $\varepsilon$ and increased circumferential $\varepsilon$ compared to controls [41]. In a study of STE between soccer players, HCM patients and controls [47], whilst radial $\varepsilon$ was significantly higher in athletes than controls, compared to HCM patients, athletes had higher values of radial and circumferential $\varepsilon$ [47], and therefore a disproportionate shift in mechanics may provide additional differential utility.

\section{Regional LV STE}

Few studies have reported comprehensive data sets for regional STE data across longitudinal, circumferential and radial planes $[36,48]$ but heterogeneity in $\varepsilon$ has been reported in all planes and is likely related to physiological structural remodelling. Knowledge of normal physiological regional adaptation may add additional relevant information when investigating abnormal global parameters. Reporting of regional $\varepsilon$ in all cardiac planes of motion in athletes involved in a range of sporting disciplines would provide valuable information in this regard.

\section{LV twist}

LV twist from helically orientated fibres is a key component of myocardial performance and can be determined by STE. LV twist data from STE is concordant with torsion measurements from tagged MRI studies in patients with a variety of cardiac pathologies [49]. In a number of studies, 
twist and apical rotation has been found to be lower in endurance (cyclists) compared to strength (weightlifters) athletes and controls despite any difference in longitudinal $\varepsilon$ [50]. Similarly, twist and apical rotation were lower in rugby football league (RFL) athletes compared to controls and associated with an increase in basal rotation and no change in longitudinal $\varepsilon$ [36]. Also, in RFL athletes, lower twist and apical rotation were observed in native Hawaiian and Pacific Island athletes compared to Caucasian counterparts, suggesting that there may also be significant ethnic differences [51]. Lower apical rotation and twist has been observed in amateur swimmers of different ages (16-48 years) with higher longitudinal $\varepsilon$ compared to controls [52]. Similarly, lower values of twist have reported in soccer players [53] and cyclists compared to controls [44]. The reduction in twist appears to be predominantly driven by reduced apical rotation, and it has been reported that the LV apex may be more dependent on sympathetic activity than the LV base [44]. This equivocal finding may be related to training induced sympathovagal balance and could be interpreted as a functional reserve to aid oxygen and substrate delivery to the muscle during exercise [27•]. In contrast, higher twist has been exhibited in endurance (marathon runners) and mixed trained (martial arts) athletes compared to controls [28] and further evidence of higher twist in resistance athletes compared to controls was reported by Beaumont et al. [26•]. Whilst the evidence suggests that twist appears to be lower in endurance athletes, some data would suggest that an increase in twist in resistance athletes is a normal phenomenon. There are few longitudinal studies assessing LV twist but there is evidence of a phasic phenomenon in twist parameters. In rowers, following 3 months of training twist was higher than baseline but after 39 months, twist was lower suggesting both acute and chronic exercise effects on this parameter [54].

Higher LV twist has been reported in hypertensive patients compared to controls with no difference between athletes and controls [39], but in contrast, twist has been also found to be similar in athletes, controls and newly diagnosed hypertensive patients [40]. An increase in twist with pathology and a preserved EF could be an early indicator of systolic dysfunction as the LV compensates for a reduction in longitudinal function in pathological left ventricular hypertrophy (LVH) [55]. No differences in twist, apical or basal rotation parameters were observed in a study between athletes, HCM patients and controls [56]. Despite this, peak twist occurred after aortic valve closure exclusively in HCM patients suggesting that a late, lower and slower untwist may be able to differentiate from pathology. In contrast, untwist was higher in elite athletes occurring earlier and faster. Untwist and untwist rate correlated with $\mathrm{E} / \mathrm{A}$ ratio and the early diastolic phase was the most discernible component of the cardiac cycle [56]. Similarly, Pacileo et al. [57] have demonstrated prolonged LV twist in cardiomyopathies. These studies indicate the potential clinical benefit of twist and untwist in differential diagnosis, not only by the use of peak values but also through a temporal assessment.

\section{Right ventricular longitudinal strain}

Resting RV $\varepsilon$ parameters in endurance athletes [8] have been reported to fall within the reported normal population range ( 18 to $-39 \%)$ [58]. There are 
reports of a higher global $\mathrm{RV} \varepsilon$ in top level rowers compared to sedentary controls [59]. Conversely, lower RV $\varepsilon$ has been reported in elite endurance athletes compared to controls, specifically in those athletes with an associated dilated RV cavity, largely due to lower basal strain [60]. This finding was reproduced in a subsequent study but with the additional finding of an increase in apical segment strain [61]. The authors proposed that normal physiological adaptation in the $\mathrm{AH}$ resulted in a base to apex gradient in RV deformation [60, 61], and whilst this gradient was also observed by Utomi et al. [62], no regional differences in $\mathrm{RV} \varepsilon$ were found in this study. Some studies also report no difference in $\mathrm{RV} \varepsilon$ between endurance and strength-based athletes [62,63]. Lower RV $\varepsilon$ has been observed in endurance (marathon runners), strength (power lifters) and mixed trained athletes (Martial arts) with increases observed with exercise [28]. In a seasonal study, despite increases in RV size in basketball and volleyball players during the season, RV function and global RV $\varepsilon$ did not change. There were some regional changes with RV apical $\varepsilon$ increasing from preseason to end season [64]. It is clear that RV $\varepsilon$ in the AH is variable and may well be related to RV enlargement/geometry [65]. Global RV $\varepsilon$ rarely falls outside of normal range but the regional changes at the apex and base may compound the diagnostic differentiation particularly as regional abnormalities have been identified in asymptomatic patients who are carriers of genetic mutations for ARVC [66].

Peak systolic RV $\varepsilon$ is significantly reduced in ARVC patients compared to controls and RV STE has been used to identify regional wall abnormalities in patients [66] making STE superior to conventional echocardiography in identifying the disease [66]. Compared to the LV, there are limited RV STE studies in athletes and there is a lack of universally

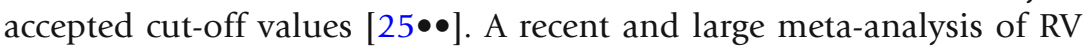
structure and function in ARVC [67] concluded that RV $\varepsilon$ is significantly lower in ARVC patients compared to controls with a range of $\mathrm{RV} \varepsilon$ in controls of -27 to $-31 \%$ and in ARVC patients of -13 to $-21 \%$. A cut-off for pathology of less than $-21 \%$ was therefore suggested.

\section{Should an exercise stimulus be considered during assessment of STE in AH?}

HCM patients have been found to have lower LV longitudinal and radial $\varepsilon$ at rest with higher circumferential $\varepsilon$ and twist compared to controls. Exercise has induced a modest increase in longitudinal $\varepsilon$ in HCM patients but not in twist whilst both parameters increased in controls [41]. In preand post-exercise studies between athletes (soccer players) and controls using hand grip exercise, EF was not different but mid to apical longitudinal $\varepsilon$ although similar at rest, was higher in athletes post-exercise. The authors suggested that exercise produces enhanced $\varepsilon$ in the mid to apical segments and may represent a regional functional reserve [68]. There is some data to suggest that an exercise stimulus is useful for differentiating DCM and AH, as identified with LVEF [69]; however, this has not been applied to $\varepsilon$ imaging and therefore, future work should aim to establish the exercise response in the differentiation of these conditions.

La Gerche et al. [61] reported a normal physiological response of the $\mathrm{RV}$ to exercise, likely due to an enhanced cardiac reserve of the basal segment. Functional athletic adaptation may not be apparent at rest and it 
was proposed on this basis that stress echocardiography may aid differential diagnosis in the RV [61]. Findings of lower segmental RV $\varepsilon$ have led to concern over possible detrimental effects of chronic exercise on RV structure and function [61,70]. Following an ultramarathon, the RV has been found to be significantly increased in size with a decrease in RV $\varepsilon$ post-race with a concomitant reduction in $\mathrm{LV} \varepsilon$. This was described by the authors as cardiac fatigue from which athletes later recovered; however, it is not yet clear what long-term impact repeated bouts of post-exercise dysfunction will have [71]. In a similar study, endurance athletes were studied at baseline, immediately post-race and 1 week post-race with decreased $\mathrm{RV}$ function, including $\mathrm{RV} \varepsilon$ post-race but mostly a complete recovery was observed after 1 week [70]. Short- and long-term effects of exercise on RV function in athletes of different discipline require further investigation.

As reduced $\mathrm{RV} \varepsilon$ can be an early marker of disease in ARVC $[14,72,73]$, the assessment of $\varepsilon$, as an early indicator for RV dysfunction [13], may be useful in the differential diagnosis of AH or pathology in PCS. Further work on RV STE parameters in athletes is required, but it is a promising technique to quantify regional RV dysfunction [66] and the elucidation of normal RV STE parameters (regional, global and temporal) at rest and during exercise has the potential to promote the clinical application of the technique. ARVC is not only a disease of the RV, as it can also have an impact on LV myocardial tissue [74]. Establishing the extent of LV involvement in ARVC may be useful in diagnostic and/or prognostic decision making.

\section{Is STE ready for daily practice in the assessment of AH?}

A major limitation of the clinical application of STE is the lack of universally accepted STE data collection protocols and normative data for healthy adults, athletes and cardiac patients. Variability in specific data can be related to vendor-to-vendor differences [75], software version and upgrades $[14,76]$ and skill of the operators performing STE analysis [22].

Despite some technical limitations, we suggest on current evidence that LV GLS and RV $\varepsilon$ should now be included in the standard echocardiographic assessment of AH. We are not suggesting that STE parameters are used solely for differentiation of physiology and pathology in AH, but used together with standard structural and functional echocardiographic parameters they may aid in the differentiation of AH from HCM, DCM and ARVC. STE has the potential to reveal early cardiac dysfunction and may corroborate conventional findings, increasing sensitivity and specificity of PCS. There is an increasing evidence base for normative GCS, GRS, regional and twist parameters in athletes, and whilst the potential of these parameters has been eluded to in this review, it is our opinion that much more work is needed before these parameters can be routinely used in $\mathrm{AH}$ assessment.

In conclusion, clinicians should be familiar with the assessment of $\mathrm{AH}$ and STE analysis should be performed by experienced operators. If STE is applied with caution and with an understanding of the limitations, global and regional $\varepsilon, \mathrm{LV}$ GLS and RV $\varepsilon$ will provide additional information to aid the differential diagnosis of physiological and pathological adaptation. 


\section{Compliance with Ethical Standards}

\section{Conflict of Interest}

Lynsey Forsythe, Keith George and David Oxborough each declare no potential conflicts of interest.

Human and Animal Rights and Informed Consent

This article does not contain any studies with human or animal subjects performed by any of the authors.

\section{Open Access}

This article is distributed under the terms of the Creative Commons Attribution 4.0 International License (http://creativecommons.org/licenses/by/4.0/), which permits unrestricted use, distribution, and reproduction in any medium, provided you give appropriate credit to the original author(s) and the source, provide a link to the Creative Commons license, and indicate if changes were made.

\section{References and Recommended Reading}

Papers of particular interest, published recently, have been highlighted as:

- Of importance

$\bullet \quad$ Of major importance

1. Pluim BM, Zwinderman AH, van der Laarse A, van der Wall EE. The Athlete's Heart: A Meta-Analysis of Cardiac Structure and Function. Circulation. 2000;101:336-44.

2. Whyte GP, George K, Sharma S, Firoozi S, Stephens N, Senior R, et al. The upper limit of physiological cardiac hypertrophy in elite male and female athletes: the British experience. Eur J Appl Physiol. 2004;92:592-7.

3. Utomi V, Oxborough D, Whyte GP, Somauroo J, Sharma S, Shave R, et al. Systematic review and metaanalysis of training mode, imaging modality and body size influences on the morphology and function of the male athlete's heart. Heart. 2013;99:1727-33.

4. D'Ascenzi F, Pelliccia A, Solari M, Piu P, Loiacono F, Anselmi F, et al. Normative Reference Values of Right Heart in Competitive Athletes: A Systematic Review and Meta-Analysis. J Am Soc Echocardiogr. 2017;30:845-58.

5. Brown B, Somauroo J, Green DJ, Wilson M, Drezner J, George K, et al. The complex phenotype of the Athlete's heart: Implications for preparticipation screening. Exerc Sport Sci Rev. 2017;45:96-104.

6. Abergel E, Chatellier G, Hagege AA, Oblak A, Linhart A, Ducardonnet A, et al. Serial left ventricular adaptations in world-class professional cyclists: Implications for disease screening and follow-up. J Am Coll Cardiol. 2004;44:144-9.
7. Finocchiaro G, Dhutia H, D'Silva A, Malhotra A, Sheikh $\mathrm{N}$, Narain R, et al. Role of Doppler diastolic parameters in differentiating physiological left ventricular hypertrophy from hypertrophic cardiomyopathy. J Am Soc Echocardiogr. 2018; https://doi.org/10.1016/j.echo. 2017.11.022.

8. Oxborough D, Sharma S, Shave R, Whyte G, Birch K, Artis $\mathrm{N}$, et al. The right ventricle of the endurance athlete: The relationship between morphology and deformation. J Am Soc Echocardiogr. 2012;25:263-71.

9. D'Ascenzi F, Pisicchio C, Caselli S, Di Paolo FM, Spataro A, Pelliccia A. RV Remodelling in Olympic Athletes. JACC Cardiovasc Imaging. 2017;10:385-93.

10. Maron BJ, Pelliccia A. The heart of trained athletes: Cardiac remodelling and the risks of sports, including sudden death. Circulation. 2006;114:1633-44.

11. Harmon KG, Drezner JA, Wilson MG, Sharma S. Incidence of Sudden Cardiac Death in Athletes. 2014;1-8. Mont L, Pelliccia A, Sharma S, Biffi A, Borjesson M, Brugada J, et al. Pre-participation cardiovascular evaluation for athletic participants to prevent sudden death: Position paper from the EHRA and the EACPR, branches of the ESC. Endorsed by APHRS, HRS, and SOLAECE'. Eur J prev Cardiol. 2017;24:41-69.

13. Mor-Avi V, Lang RM, Badano LP, Belohlavek M, Cardim NM, Derumeaux G, et al. Current and evolving echocardiographic techniques for the quantitative 
evaluation of cardiac mechanics: ASE/EAE consensus statement on methodology and indications endorsed by the Japanese Society of Echocardiography. J Am Soc Echocardiogr. 2011;24:277-313.

14. Smiseth OA, Torp H, Opdahl A, Haugaa KH, Urheim S. Myocardial strain imaging: How useful is it in clinical decision making? Eur Heart J. 2016;37:1196-207.

15. Ho SY, Nihoyannopoulos P. Anatomy, echocardiography, and normal right ventricular dimensions. Heart. 2006;92:2-14.

16. Lang RM, Badano LP, Mor-Avi V, Afilalo J, Armstrong A, Ernande L, et al. Recommendations for Cardiac Chamber Quantification by Echocardiography in Adults: An Update from the American Society of Echocardiography and the European Association of Cardiovascular Imaging. J Am Soc Echocardiogr. 2015;28:1-39.

17. Collier P, Phelan D, Klein A. A Test in Context: Myocardial Strain Measured by Speckle-Tracking Echocardiography. JACC. 2017;69:1043-56.

18. Maclver DH, Townsend M. A novel mechanism of heart failure with normal ejection fraction. Heart. 2008;94:446-9.

19. MacIver DH. A new method for quantification of left ventricular systolic function using a corrected ejection fraction. Eur J Echocardiogr. 2011;12:228-34.

20. MacIver DH, Dayer MJ. An alternative approach to understanding the pathophysiological mechanisms of chronic heart failure. Int J Cardiol. 2012;154:102-10.

21. Nesto RW, Kowalchuk GJ. The Ischemic cascade: temporal sequence of hemodynamic, electrocardiographic and symptomatic expressions of ischemia. Am J Cardiol. 1987;59:23C-30C.

22. Plana JC, Galderisi M, Barac A, Ewer MS, Ky B, ScherrerCrosbie M, et al. Expert consensus for multimodality imaging evaluation of adult patients during and after cancer therapy: A report from the American Society of Echocardiography and the European Association of Cardiovascular Imaging. Eur Heart J Cardiovasc Imaging. 2014;15:1063-93.

23. Tops LF, Delgado V, Marsan NA, Bax JJ. Myocardial strain to detect subtle left ventricular systolic dysfunction. Eur J Heart Fail. 2017;19:307-13.

24. Biering-Sørensen T, Biering-Sørensen SR, Olsen FJ, Sengeløv M, Jørgensen PG, Mogelvang R, et al. Global Longitudinal Strain by Echocardiography Predicts Long-Term Risk of Cardiovascular Morbidity and Mortality in a Low-Risk General Population: The Copenhagen City Heart Study. Circ Cardiovasc Imaging. 2017;10:e005521. https://doi.org/10.1161/ circimaging.116.005521.

25.• Pelliccia A, Caselli S, Sharma S, Basso C, Bax JJ, Corrado D, et al. European Association of Preventive Cardiology (EAPC) and European Association of Cardiovascular Imaging (EACVI) joint position statement: recommendations for the indication and interpretation of cardiovascular imaging in the evaluation of the athlete's heart. Eur Heart J. 2017;0:1-27. https://doi.org/ 10.1093/eurheartj/ehx532/4210363.
A Joint postion statement for the cardiovascular imaging of the $\mathrm{AH}$.

26. Beaumont A, Grace F, Richards J, Hough J, Oxborough D, Sculthorpe N. Left Ventricular Speckle TrackingDerived Cardiac Strain and Cardiac Twist Mechanics in Athletes:

A Systematic Review and Meta-Analysis of Controlled Studies. Sport Med. 2017;47:1145-70. A Review and Meta-Analysis of LV STE in athletes which contributes to the translation of this novel technique into clinical practice.

27. D'Ascenzi F, Caselli S, Solari M, Pelliccia A, Cameli M, Focardi M, et al. Novel echocardiographic techniques for the evaluation of athletes' heart: A focus on speckletracking echocardiography. Eur J Prev Cardiol. 2016;23:437-46.

A Review of LV and RV STE in AH which contributes to the translation of this novel technique into clinical practice.

28. Vitarelli A, Capotosto L, Placanica G, Caranci F, Pergolini M, Zardo F, et al. Comprehensive assessment of biventricular function and aortic stiffness in athletes with different forms of training by three-dimensional echocardiography and strain imaging. Eur Heart J Cardiovasc Imaging. 2013;14:1010-20.

29. Simsek Z, Hakan Tas M, Degirmenci H, Gokhan Yazici A, Ipek E, Duman H, et al. Speckle tracking echocardiographic analysis of left ventricular systolic and diastolic functions of young elite athletes with eccentric and concentric type of cardiac remodelling. Echocardiography. 2013;30:1202-8.

30. Utomi V, Oxborough D, Ashley E, Lord R, Fletcher S, Stembridge $\mathrm{M}$, et al. Predominance of normal left ventricular geometry in the male "athlete"s heart'. Heart. 2014;100:1264-71.

31. Stefani L, Pedrizzetti G, De Luca A, Mercuri R, Innocenti G, Galanti G. Real-time evaluation of longitudinal peak systolic strain (speckle tracking measurement) in left and right ventricles of athletes. Cardiovasc Ultrasound. 2009;7:17. https://doi.org/10.1186/14767120-7-17.

32. Nottin S, Doucende G, Schuster I, Tanguy S, Dauzat M, Obert P. Alteration in left ventricular strains and torsional mechanics after ultralong duration exercise in athletes. Circ Cardiovasc Imaging. 2009;2:323-30.

33. Kansal MM, Lester SJ, Surapaneni P, Sengupta PP, Appleton $\mathrm{CP}$, Ommen SR, et al. Usefulness of twodimensional and speckle tracking echocardiography in "grey zone" left ventricular hypertrophy to differentiate professional football player's heart from hypertrophic cardiomyopathy. Am J Cardiol 2011;108:1322-1326.

34. Caselli S, Montesanti D, Autore C, Di Paolo FM, Pisicchio C, Squeo MR, et al. Patterns of left ventricular longitudinal strain and strain rate in olympic athletes. J Am Soc Echocardiogr. 2015;28:245-53.

35. Oxborough D, Heemels A, Somauroo J, McClean G, Mistry $\mathrm{P}$, Lord $\mathrm{R}$, et al. Left and right ventricular longitudinal strain-volume/area relationships in elite athletes. Int J Cardiovasc Imaging. 2016;32:1199-211.

36. Forsythe L, MacIver DH, Johnson C, George K, Somauroo J, Papadakis $\mathrm{M}$, et al. The relationship 
between left ventricular structure and function in the elite rugby football league athlete as determined by conventional echocardiography and myocardial strain imaging. Int J Cardiol. 2018;261:211-7.

37. Giraldeau G, Kobayashi Y, Finocchiaro G, Wheeler M, Perez M, Kuznetsova T, et al. Gender Differences in Ventricular Remodelling and Function in College Athletes, Insights from Lean Body Mass Scaling and Deformation Imaging. Am J Cardiol. 2015;116:1610-6.

38. D'Ascenzi F, Pelliccia A, Alvino F, Solari M, Loffreno A, Cameli $\mathrm{M}$, et al. Effects of training on LV strain in competitive athletes. Heart. 2015;101:1834-9.

39. Cappelli F, Toncelli L, Cappelli B, De Luca A, Stefani L, Maffulli N, et al. Adaptive or maladaptive hypertrophy, different spatial distribution of myocardial contraction. Clini Physiol Funct Imaging. 2010;30:6-12.

40. Galderisi M, Lomoriello VS, Santoro A, Esposito R, Olibet M, Raia R. Di Minno et al. Differences of myocardial systolic deformation and correlates of diastolic function in competitive rowers and young hypertensives: a speckle tracking echocardiography study. J Am Soc Echocardiogr. 2010;23:1190-8.

41. Soullier C, Obert P, Doucende G, Nottin S, Cade S, Perez-Martin A, et al. Exercise response in hypertrophic cardiomyopathy: Blunted left ventricular deformational and twisting reserve with altered systolicdiastolic coupling. Circ Cardiovasc Imaging. 2012;5:324-32.

42. Butz T, Van Buuren F, Mellwig KP, Langer C, Plehn G, Meissner A, et al. Two-dimensional strain analysis of the global and regional myocardial function for the differentiation of pathologic and physiologic left ventricular hypertrophy: A study in athletes and in patients with hypertrophic cardiomyopathy. Int J Cardiovasc Imaging. 2011;27:91-100.

43. Okada M, Tanaka H, Matsumoto K, Ryo K, Kawai H, Hirata KI. Subclinical myocardial dysfunction in patients with reverse-remodelled dilated cardiomyopathy. J Am Soc Echocardiogr. 2012;25:726-32.

44. Nottin S, Doucende G, Schuster-Beck I, Dauzat M, Obert P. Alteration in left ventricular normal and shear strains evaluated by 2D-strain echocardiography in the athlete's heart. J Physiol. 2008;586:4721-33.

45. Donal E, Rozoy T, Kervio G, Schnell F, Mabo P, Carré F. Comparison of the heart function adaptation in trained and sedentary men after 50 and before 35 years of age. Am J Cardiol. 2011;108:1029-37.

46. Szauder I, Kovács A, Pavlik G. Comparison of left ventricular mechanics in runners versus bodybuilders using speckle tracking echocardiography. Cardiovasc Ultrasound. 2015;13(1):1-7.

47. Richand V, Lafitte S, Reant P, Serri K, Lafitte M, Brette S, et al. An Ultrasound Speckle Tracking (Two-

Dimensional Strain) Analysis of Myocardial Deformation in Professional Soccer Players Compared With Healthy Subjects and Hypertrophic Cardiomyopathy. Am J Cardiol. 2007;100:128-32.

48. Baggish AL, Yared K, Wang F, Weiner RB, Jr AMH, Picard $\mathrm{MH}$, et al. The impact of endurance exercise training on left ventricular systolic mechanics. Am J Physiol Heart Circ Physiol. 2008;295:H1109-16.

49. Notomi Y, Lysyansky P, Setser RM, Shiota T, Popović $\mathrm{ZB}$, Martin-Miklovic MG, et al. Measurement of ventricular torsion by two-dimensional ultrasound speckle tracking imaging. J Am Coll Cardiol. 2005;45:203441.

50. Santoro A, Alvino F, Antonelli G, Caputo M, Padeletti M, Lisi M, et al. Endurance and strength athlete's heart: Analysis of myocardial deformation by speckle tracking echocardiography. J Cardiovasc Ultrasound. 2014;22:196-204.

51. Johnson C, Forsythe L, Somauroo J, Papadakis M, George K, Oxborough D. Cardiac structure and function in elite Native Hawaiian and Pacific Islander Rugby Football League athletes: an exploratory study. Int J Cardiovasc Imaging. 2018;34:725-34.

52. Santoro A, Alvino F, Antonelli G, Cassano FE, De Vito $\mathrm{R}$, Cameli $\mathrm{M}$, et al. Age related diastolic function in amateur athletes. Int J Cardiovasc Imaging. 2015;31:567-73.

53. Zócalo Y, Guevara E, Bia D, Giacche E, Pessana F, Peidro $\mathrm{R}$, et al. A reduction in the magnitude and velocity of left ventricular torsion may be associated with increased left ventricular efficiency: evaluation by speckle-tracking echocardiography. 2008;61:705-13.

54. Weiner RB, DeLuca JR, Wang F, Lin J, Wasfy MM, Berkstresser B, et al. Exercise-Induced Left Ventricular Remodelling Among Competitive Athletes: A phasic phenomenon. Circ Cardiovasc Imaging. 2015;8:e003651. https://doi.org/10.1161/circimaging. 115.003651 .

55. Santoro A, Alvino F, Antonelli G, Zacà V, Benincasa S, Lunghetti $S$, et al. Left ventricular twisting modifications in patients with left ventricular concentric hypertrophy at increasing after-load conditions. Echocardiography. 2014;31:1265-73.

56. Kovacs A, Apor A, Nagy A, Vago H, Toth A, Kovats T, et al. Left Ventricular Untwisting in Athlete's Heart: Key Role in Early Diastolic Filling? Int J Sports Med. 2014;35:259-64.

57. Pacileo G, Baldini L, Limongelli G, Di Salvo G, Iacomino M, Capogrosso C, et al. Prolonged left ventricular twist in cardiomyopathies: A potential link between systolic and diastolic dysfunction. Eur J Echocardiogr. 2011;12:841-9.

58. Rudski LG, Lai WW, Afilalo J, Hua L, Handschumacher MD, Chandrasekaran K, et al. Guidelines for the Echocardiographic Assessment of the Right Heart in Adults: A Report from the American Society of Echocardiography. J Am Soc Echocardiogr. 2010;23:685-713.

59. Esposito R, Galderisi M, Schiano-Lomoriello V, Santoro A, De Palma D, Ippolito R, et al. Nonsymmetric myocardial contribution to supranormal right ventricular function in the athletes' heart: combined assessment by speckle tracking and real time threedimensional echocardiography. Echocardiography. 2014;31:996-1004. 
60. Teske AJ, Prakken NH, De Boeck BW, Velthuis BK, Martens EP, Doevendans PA, et al. Echocardiographic tissue deformation imaging of right ventricular systolic function in endurance athletes. Eur Heart J. 2009;30:969-77.

61. La Gerche A, Burns AT, D'Hooge J, MacIsaac AI, Heidbüchel H, Prior DL. Exercise strain rate imaging demonstrates normal right ventricular contractile reserve and clarifies ambiguous resting measures in endurance athletes. J Am Soc Echocardiogr. 2012;25:253-62.

62. Utomi V, Oxborough D, Ashley E, Lord R, Fletcher S, Stembridge $\mathrm{M}$, et al. The impact of chronic endurance and resistance training upon the right ventricular phenotype in male athletes. Eur J Appl Physiol. 2015;115:1673-82.

63. Pagourelias ED, Kouidi E, Efthimiadis GK, Deligiannis A, Geleris P, Vassilikos V. Right atrial and ventricular adaptations to training in male caucasian athletes: An echocardiographic study. J Am Soc Echocardiogr. 2013;26(11):1344-52.

64. D'Ascenzi F, Pelliccia A, Corrado D, Cameli M, Curci V, Alvino $\mathrm{F}$, et al. Right ventricular remodelling induced by exercise training in competitive athletes. Eur Heart J Cardiovasc Imaging. 2016;17:301-7.

65. Qasem M, George K, Somauroo J, Forsythe L, Brown B, Oxborough D. Influence of different dynamic sporting disciplines on right ventricular Structure and function in elite male athletes. Int J Cardiovasc Imaging. 2018; https://doi.org/10.1007/s10554-018-1316-2.

66. Teske AJ, Cox MG, De Boeck BW, Doevendans PA, Hauer RN, Cramer MJ. Echocardiographic Tissue Deformation Imaging Quantifies Abnormal Regional Right Ventricular Function in Arrhythmogenic Right Ventricular Dysplasia/Cardiomyopathy. J Am Soc Echocardiogr. 2009;22:920-7.

67. Qasem M, Utomi V, George K, Somauroo J, Zaidi A, Forsythe L, et al. A Meta-Analysis for the Echocardiographic Assessment of Right Ventricular Structure and Function in ARVC. Echo Res Prac. 2016;3:95-104.

68. Stefani L, Toncelli L, Di Tante V, Vono MCR, Cappelli B, Pedrizzetti G, et al. Supernormal functional reserve of apical segments in elite soccer players: An ultrasound speckle tracking handgrip stress study. Cardiovasc Ultrasound. 2008;6:1-8.

69. Claessen G, Schnell F, Bogaert J, Claeys M, Pattyn N, De Buck F, et al. Exercise cardiac magnetic resonance to differentiate athlete's heart from structural heart disease. Eur Heart J Cardiovasc Imaging. 2018; https://doi. org/10.1093/ehjci/jey050.

70. La Gerche A, Burns AT, Mooney DJ, Inder WJ, Taylor AJ, Bogaert J, et al. Exercise-induced right ventricular dysfunction and structural remodelling in endurance athletes. Eur Heart J. 2012;33:998-1006.

71. Oxborough D, Shave R, Warburton D, Williams K, Oxborough A, Charlesworth S, et al. Dilatation and dysfunction of the right ventricle immediately after ultraendurance exercise: Exploratory insights from conventional two-dimensional and speckle tracking echocardiography. Circ Cardiovasc Imaging. 2011;4:253-63.

72. Saberniak J, Hasselberg NE, Borgquist R, Platonov PG, Sarvari SI, Smith HJ, et al. Vigorous physical activity impairs myocardial function in patients with arrhythmogenic right ventricular cardiomyopathy and in mutation positive family members. Eur J Heart Fail. 2014;16:1337-44.

73. Sarvari SI, Haugaa KH, Anfinsen OG, Leren TP, Smiseth $\mathrm{OA}$, Kongsgaard E, et al. Right ventricular mechanical dispersion is related to malignant arrhythmias: A study of patients with arrhythmogenic right ventricular cardiomyopathy and subclinical right ventricular dysfunction. Eur Heart J. 2011;32:1089-96.

74. Coats CJ, Quarta G, Flett AS, Pantazis AA, McKenna WJ, Moon JC. Arrhythmogenic left ventricular cardiomyopathy. Circulation. 2009;120:2613-4.

75. Farsalinos KE, Daraban AM, Unlu S, Thomas JD, Badano LP, Voigt JU. Head-to-head comparison of global longitudinal strain measurements among nine different vendors: The EACVI/ASE inter-vendor comparison study'. J Am Soc Echocardiogr. 2015;28:117181.

76. Nagata Y, Takeuchi M, Mizukoshi K, Wu VC, Lin FC, Negishi K, et al. Intervendor variability of twodimensional strain using vendor-specific and vendorindependent software'. J Am Soc Echocardiogr. 2015;28:630-41. 